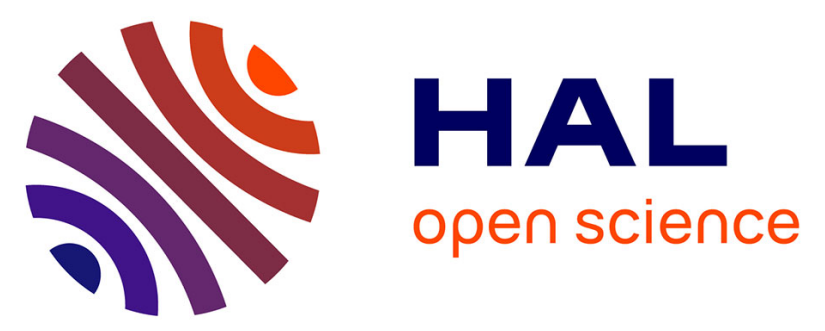

\title{
Assessment of the Impact of Frequency Containment Control and Synthetic Inertia on Intermittent Energies Generators Integration
}

Thibaut Kovaltchouk, Vincent Debusschere, Seddik Bacha, Mirko Fiacchini, Mazen Alamir

\section{To cite this version:}

Thibaut Kovaltchouk, Vincent Debusschere, Seddik Bacha, Mirko Fiacchini, Mazen Alamir. Assessment of the Impact of Frequency Containment Control and Synthetic Inertia on Intermittent Energies Generators Integration. EVER 2016 - 11th International Conference on Ecological Vehicles and Renewable Energies, Apr 2016, Monte Carlo, Monaco. 10.1109/EVER.2016.7476361 . hal-01321296

\section{HAL Id: hal-01321296 \\ https://hal.science/hal-01321296}

Submitted on 25 May 2016

HAL is a multi-disciplinary open access archive for the deposit and dissemination of scientific research documents, whether they are published or not. The documents may come from teaching and research institutions in France or abroad, or from public or private research centers.
L'archive ouverte pluridisciplinaire HAL, est destinée au dépôt et à la diffusion de documents scientifiques de niveau recherche, publiés ou non, émanant des établissements d'enseignement et de recherche français ou étrangers, des laboratoires publics ou privés. 


\section{Assessment of the Impact of Frequency Containment Control and Synthetic Inertia on Intermittent Energies Generators Integration}

\author{
Thibaut Kovaltchouk, \\ Vincent Debusschere, Seddik Bacha \\ Univ. Grenoble Alpes \\ G2Elab (UMR CNRS 5269) \\ F-38000 Grenoble, France \\ thibaut.kovaltchouk@g2elab.grenoble-inp.fr
}

\author{
Mirko Fiacchini, Mazen Alamir \\ Univ. Grenoble Alpes \\ gipsa-lab (UMR CNRS 5216) \\ F-38000 Grenoble, France
}

\begin{abstract}
The increasing power generation out of intermittent renewable energy sources will result in a reduction of the grid stability if no compensatory actions are taken. This issue may lead to future obligations for energy providers. This paper studies the implication of the future obligations for generators in Europe according to the recommendations of ENTSO-E, in particular the obligation for some generators to have a synthetic (or virtual) inertia and a frequency sensitive control. These obligations will be described in details in the paper, in particular their effect on the grid management and stability. The impact of this new actions on the energy production will be discussed. The continental European grid frequency is used as an example.
\end{abstract}

Keywords-Frequency Sensitive Control, Synthetic Inertia, Renewable Energy, Power Grid Vulnerability, Grid Integration

\section{INTRODUCTION}

The grid integration of some renewables (in particular those from intermittent primary sources) has always been a technical and political difficulty. The negative impact of renewable energy on the power grid resilience, especially from a frequency point of view, has been studied deeply [2], in particular in relative small grid (island) [3], [4].

(C) 2016 IEEE. Personal use of this material is permitted. Permission from IEEE must be obtained for all other uses, including reprinting/republishing this material for advertising or promotional purposes, collecting new collected works for resale or redistribution to servers or lists, or reuse of any copyrighted component of this work in other works

T. Kovaltchouk, V. Debusschere, S. Bacha, M. Fiacchini and M. Alamir, "Assessment of the impact of frequency containment control and synthetic inertia on intermittent energies generators integration," 2016 Eleventh International Conference on Ecological Vehicles and Renewable Energies (EVER), Monte Carlo, Monaco, 2016, pp. 1-8. doi: 10.1109/EVER.2016.7476361
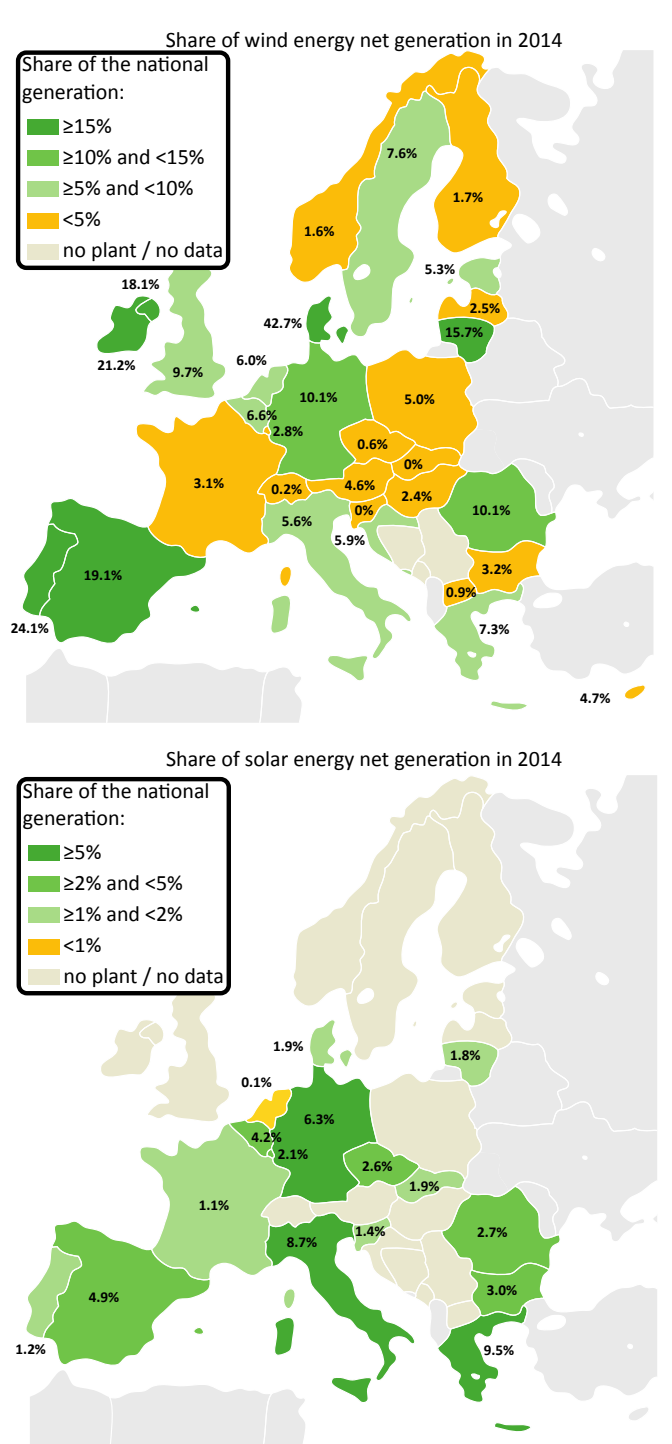

Fig. 1. Share of wind and solar energy in the production for some ENTSO-E countries (inspired by [1]) 
The significant growth of these energies, in particular wind and solar (see Fig. 1), is forcing to find new solutions. Recently, special attention has been paid to the capability for renewable systems to participate in ancillary services [5]-[9].

Clearly, these studies have influenced the European Network of Transmission System Operators for Electricity (ENTSO-E) Grid code for generators connection requirements [10], specially concerning frequency regulation. The ENTSO-E represents 41 Transmission System Operators (TSOs) from 34 European countries. We will focus this paper on the description of two important part of this code: the frequency sensitive control and the synthetic inertia, in order to evaluate the implications of this grid code on the control of renewable based generators.

\section{NOVEl Obligations FOR GENERATORS}

\section{A. ENTSO-E Generators classification}

ENTSO-E uses a classification of generators (A,B,C and $\mathrm{D}$ ) according to their maximum capacity and the voltage of their connection point [10]. Typically, type $\mathrm{A}$ and $\mathrm{B}$ corresponds to small generators connected to the electric power distribution system and type $\mathrm{C}$ and $\mathrm{D}$ corresponds to large generators connected to the electric transmission system.

Each TSO must define these types according to the maximum threshold of Table I. Besides, all the generators connected at $110 \mathrm{kV}$ or above are automatically of type D. The synchronous areas used in this table are illustrated in Fig. 2.

TABLE I. MAXIMUM CAPACITY THRESHOLD FROM WHICH ON A Power Generating Module is of Type B, C OR D [10]

\begin{tabular}{|c|c|c|c|}
\hline Synchronous Area & Type B & Type C & Type D \\
\hline Continental Europe & $1 \mathrm{MW}$ & $50 \mathrm{MW}$ & $75 \mathrm{MW}$ \\
\hline Nordic & $1.5 \mathrm{MW}$ & $10 \mathrm{MW}$ & $30 \mathrm{MW}$ \\
\hline Great Britain & $1 \mathrm{MW}$ & $10 \mathrm{MW}$ & $30 \mathrm{MW}$ \\
\hline Ireland & $0.1 \mathrm{MW}$ & $5 \mathrm{MW}$ & $10 \mathrm{MW}$ \\
\hline Baltic & $0.5 \mathrm{MW}$ & $10 \mathrm{MW}$ & $15 \mathrm{MW}$ \\
\hline
\end{tabular}

Clearly, these thresholds depend on the size in term of capacity of the synchronous area, as can be seen in Fig. 3. Since the Baltic area is synchronous connected with the IPS/UPS area (Integrated Power System/Unified Power System of Russia), the generating capacity of this area has been added to the Baltic countries. Obviously, the weaker grid is, the more generators are needed to participate to the frequency stability in these areas.

The new obligations for synthetic inertia and frequency sensitive control are just for the largest generators (type C and D) [12].

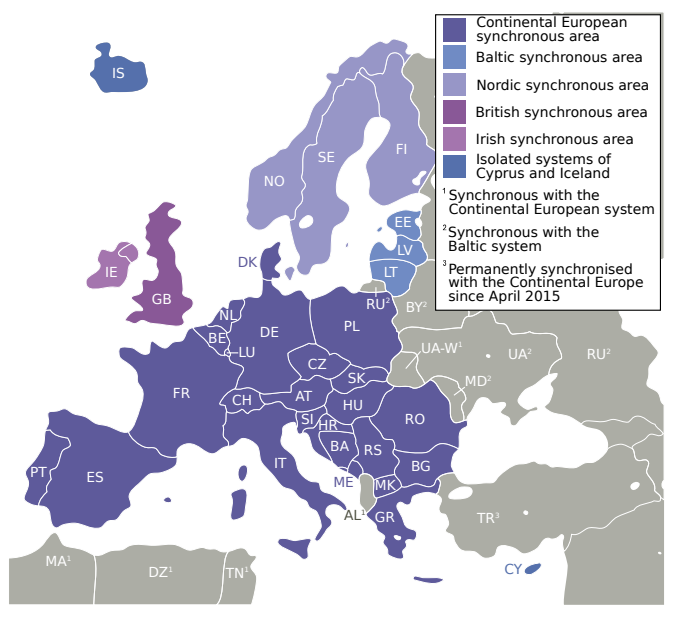

Fig. 2. The geographical area covered by ENTSO-Es member TSOs is divided into five synchronous areas and two isolated systems (Cyprus and Iceland) [11]

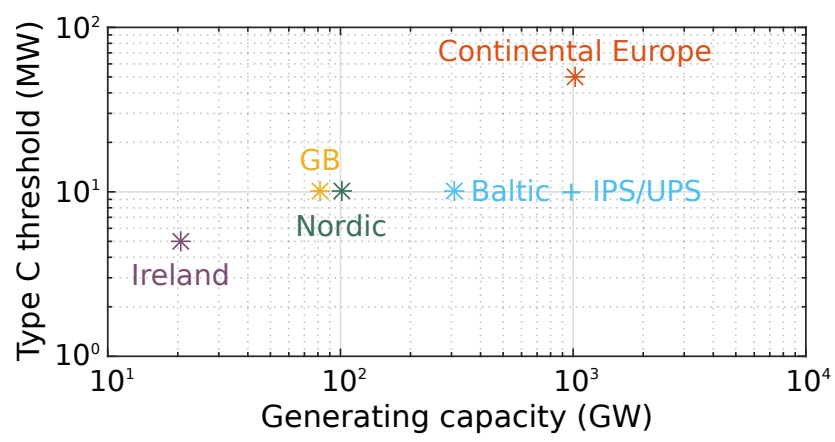

Fig. 3. Maximum capacity threshold for type $\mathrm{C}$ as a function of the net generating capacity of the synchronous areas

\section{B. Synthetic Inertia}

Each rotating electrical machine (generator or motor) directly connected to the grid have a mechanical inertia. The addition of all theses inertia results in an equivalent electrical inertia $J_{\text {total }}$. The frequency deviation depends on this inertia:

$$
\begin{aligned}
\frac{\mathrm{d}}{\mathrm{d} t}\left(\frac{1}{2} J_{\text {total }} \omega^{2}\right) & =P_{g}-P_{l} \\
J_{\text {total }} \omega \frac{\mathrm{d} \omega}{\mathrm{d} t} & =P_{g}-P_{l}
\end{aligned}
$$

with $P_{g}$ the generated power, $P_{l}$, the power demand and $\omega=2 \pi f$ the electrical pulsation.

The global inertia constant $H_{\text {total }}$, in s, is the normalization of the kinetic energy by the sum of the apparent power of the connected generators $S_{\text {total }}$ :

$$
H_{\text {total }}=\frac{J_{\text {total }} \omega^{2}}{2 S_{\text {total }}}
$$


So we can rewrite (2) with this notation, and we have:

$$
\begin{aligned}
& \frac{2 H_{\text {total }}}{\omega} \frac{\mathrm{d} \omega}{\mathrm{d} t}=\frac{P_{g}-P_{l}}{S_{\text {total }}} \\
& \frac{2 H_{\text {total }}}{f} \frac{\mathrm{d} f}{\mathrm{~d} t}=\frac{P_{g}-P_{l}}{S_{\text {total }}}
\end{aligned}
$$

The temporal derivative of the frequency $\frac{\mathrm{d} f}{\mathrm{~d} t}$ is called Rate-Of-Change-Of-Frequency (RoCoF) in $[\mathrm{Hz} / \mathrm{s}]$. Some relays use this value to detect islanded operation. The typical incident case scenario corresponds to a case where a major unit of generation shut down with a low load. The relative original disbalance can have value from $1.7 \%$ (reference incident for the continental Europe) to $8 \%$ (Great-Britain and Ireland). With typical value of $H_{\text {total }}$ between 4 to $6 \mathrm{~s}$ [13], [14], exceptional RoCoF values are between $70 \mathrm{mHz} / \mathrm{s}$ and $500 \mathrm{mHz} / \mathrm{s}$ for $50 \mathrm{~Hz}$ grids, depending on generators technologies and grid total capacity.

The power electronics allows static DC/AC conversion for photovoltaic power generation [8], [15] and variable speed generation which is more suitable for the energy production optimization. Two architectures are mostly used: Doubly Fed Induction Generators (DFIG) [16] and Fully-Fed (Induction or Synchronous) Generators (using back-to-back AC/DC/AC converters).

These architectures decouple the mechanical and electrical systems, thus preventing the generator from responding to system frequency changes like a traditional synchronous generator. Controls that allow inertia-like response have several name in the literature: synchronverters [17], Fast Frequency Response [8], virtual [18], artificial [5], [19], emulated [20] or synthetic inertia [7], [9]. Examples of synthetic inertia controls commercially available for Wind Turbine Generators are: General Electric WindINERTIA [21] and ENERCON Inertia Emulation [22], [23]. At the best of our knowledge, it exists no remuneration for providing inertia to the grid.

In order to emulate a synthetic inertia, a power reserve $\Delta P_{i}$ must be controlled with the following law :

$$
\Delta P_{i}=\frac{2 P_{\max } H_{\text {gen }}}{f_{n}} \frac{\mathrm{d} f}{\mathrm{~d} t}
$$

with $P_{\max }$, the capacity of the generator, $H_{g e n}$, the generator inertia constant and $f_{n}$ the nominal frequency. Synthetic inertia control must be very rapid ( 2 seconds for full response [23]) in order to emulate the inertia properly.

In order to size this reserve, we must know the maximum allowed RoCoF value :

$$
\left(\Delta P_{i}\right)_{\max }=\frac{2 P_{\max } H_{g e n}}{f_{n}}\left(\frac{\mathrm{d} f}{\mathrm{~d} t}\right)_{\max }
$$

This maximum value is around $0.5 \mathrm{~Hz} / \mathrm{s}$ for Great Britain generators. In this context, the size of the power reserve would be around $2 \% / \mathrm{s}$. So, with a $5 \%$ reserve, it would be possible to create an inertia constant of $2.5 \mathrm{~s}$ for all $\mathrm{RoCoF}$ from $-0.5 \mathrm{~Hz} / \mathrm{s}$ to $+0.5 \mathrm{~Hz} / \mathrm{s}$.

Of course, all the intermittent energies have not the same capabilities for synthetic inertia. Some technologies possesses intrinsic energy buffers from rotating parts (like wind turbines, tidal turbines, Oscillating Water Columns), from moving parts (like Direct-Drive Wave Energy Converters), from hydraulic reservoirs (like overtopping devices) or from thermal storage (like solar thermal energy). For these technologies, the obligation to provide synthetic inertia can lead to none or negligible economical consequences by using the already existing stored energy (hidden inertia as called in some studies). Each technology needs to quantify this capability in term of synthetic inertia.

On the contrary, some technologies (in particular photovoltaics) possesses negligible intrinsic energy. In this case, the constitution of a reserve by deloading (power set-point below maximum power, also called generation shedding) is mandatory in order to create a synthetic inertia. Such permanent reserve would result in a significant loss on energy production. So this reserve should be used only in some rare cases, only at the time the grid is the weaker (typically during low consumption periods).

\section{Frequency Sensitive Control}

The frequency sensitive mode describes in the ENTSO-E code is a classical primary frequency control or frequency containment control. The control of this reserve $\Delta P_{c}$ is proportional to the frequency deviation with a saturation effect:

$$
\Delta P_{c}=-P_{\max } \operatorname{sgn}\left(f-f_{n}\right) \min \left(\frac{\left|f-f_{n}\right|}{D \cdot f_{n}}, R_{c}\right)
$$

with $D$ the droop, $R_{c}$, the containment reserve. All grid codes allow a deadband $(d b)$. If the deviation is inside this deadband, no power response is required. The recommended range for $R_{c}, D$ and $d b$ are given in Table II. The response time asked for this reserve is much less than for the inertia reserve: the maximum admissible initial delay is $2 \mathrm{~s}$ and the maximum admissible delay for full activation is $30 \mathrm{~s}$.

TABLE II. FREQUENCY SENSITIVE MODE PARAMETERS [?], [10], [24]

\begin{tabular}{|c|c|c|c|}
\hline Parameters & ENTSO-E & France & Great Britain \\
\hline Reserve $R_{c}$ & $1.5-10 \%$ & $\geq 2.5 \%$ & $\geq 10 \%$ \\
\hline Droop $D$ & $2-12 \%$ & $3-16 \%$ & $3-5 \%$ \\
\hline Deadband $d b$ & $\pm 10-30 \mathrm{mHz}$ & $\pm 10 \mathrm{mHz}$ & $\pm 15 \mathrm{mHz}$ \\
\hline
\end{tabular}


The actual French remuneration for the containment reserve is $9.16 € / \mathrm{MW} /(1 / 2 \mathrm{~h})$ : it is the availability of the reserve that is remunerated $\left(R_{c}\right.$ at a half hour time step) [?]. Deload operation in order to provide reserve is economically interesting for a generator if the reserve remuneration is superior to the feed-in tariff. But official feed-in tariff for ocean energy in France for example (wave and tidal) is $150 € / \mathrm{MWh}$ (more than 8 times superior than the reserve price). This raises the question of distinguishing ancillary services market and grid code requirement.

The actual Great Britain code proposes a nonsymmetric frequency sensitive mode control, as can be seen in Fig. 4. Indeed, when no permanent deload is required by the TSO, the frequency containment service is used only in case of over-frequency.
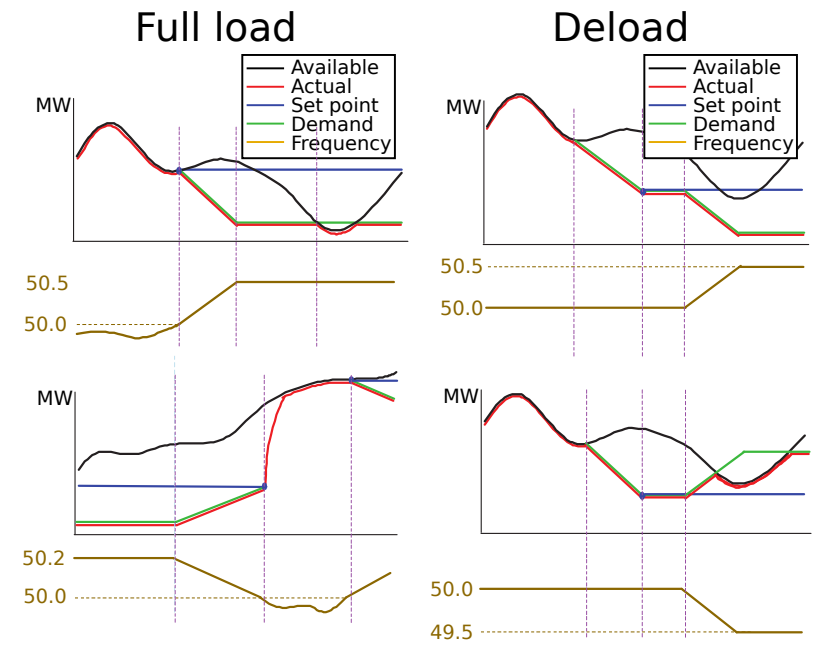

Fig. 4. Two full load and two deload (or generation shedding) scenarios in the Great Britain grid code (inspired by [25])

\section{STUdies}

\section{A. Test case of a major loss of production}

The test case presented here is inspired by those presented for example in the following papers [7], [8], [26]. The main characteristics of this test case are presented in Table III. Such major frequency deviations come from a sudden imbalance, due to the loss of a large producer or a major line.

\section{TABLE III. TEST CASE PARAMETERS}

\begin{tabular}{|c|c|}
\hline Parameters & Values \\
\hline Initial RoCoF & $-0.3 \mathrm{~Hz} / \mathrm{s}$ \\
\hline Frequency nadir (lowest frequency) & $49.6 \mathrm{~Hz}$ \\
\hline Steady state frequency deviation & $49.87 \mathrm{~Hz}$ \\
\hline
\end{tabular}

The architecture of the control is shown in Fig. 5. The blue part represents the synthetic inertia and the green part the sensitive frequency control (or containment control). The output is a power set-point which has to be added to the power output. The inertia synthesis has a $20 \mathrm{~ms}$ time constant with an inertia constant of $5 \mathrm{~s}$ and the containment control has a time constant of $3 \mathrm{~s}$, a droop of $5 \%$ and a dead-band of $\pm 10 \mathrm{mHz}$. Both are limited by a reserve of $10 \%$, but this limit is not reached during our test case. These values are considered here as a typical example.

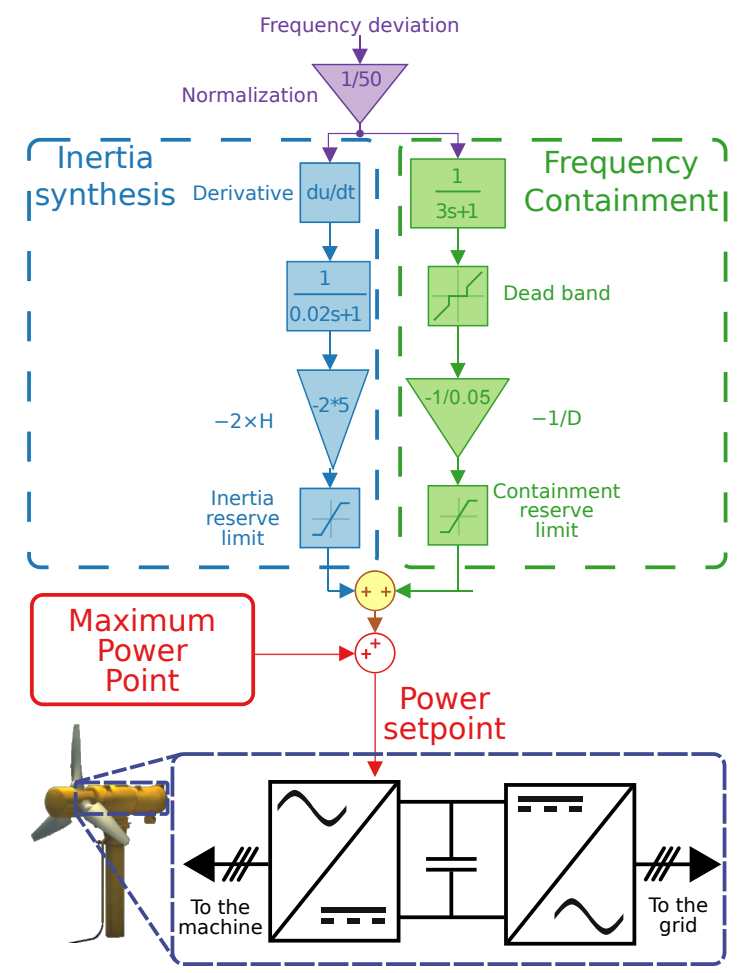

Fig. 5. Structure of the two controls (inertia and containment): example of an individual tidal turbine with a back-to-back AC/DC/AC converter

On this test case, we can see the complementary between the inertia response and the frequency sensitive response in Fig 6. Indeed, the inertia synthesis is very rapid and can help to limit the $\mathrm{RoCoF}$ value and the frequency nadir (lowest frequency). The containment control is much more slow, but helps to limit the frequency nadir and the steady-state frequency deviation.

It is also noticeable that the power fluctuations of each control can partially be compensated when added (fluctuations of the total curve compared to the inertia and containment curves).

\section{B. Continental Europe frequency analysis}

RTE published freely the frequency in the continental area with a time-step of $10 \mathrm{~s}$ since the 1st October 2014 [27]. We can see for example the frequency measured by RTE for three different days in Fig. 7.

So, we now can study one year of frequency deviation, from the 1st October 2014 to the 30th September 


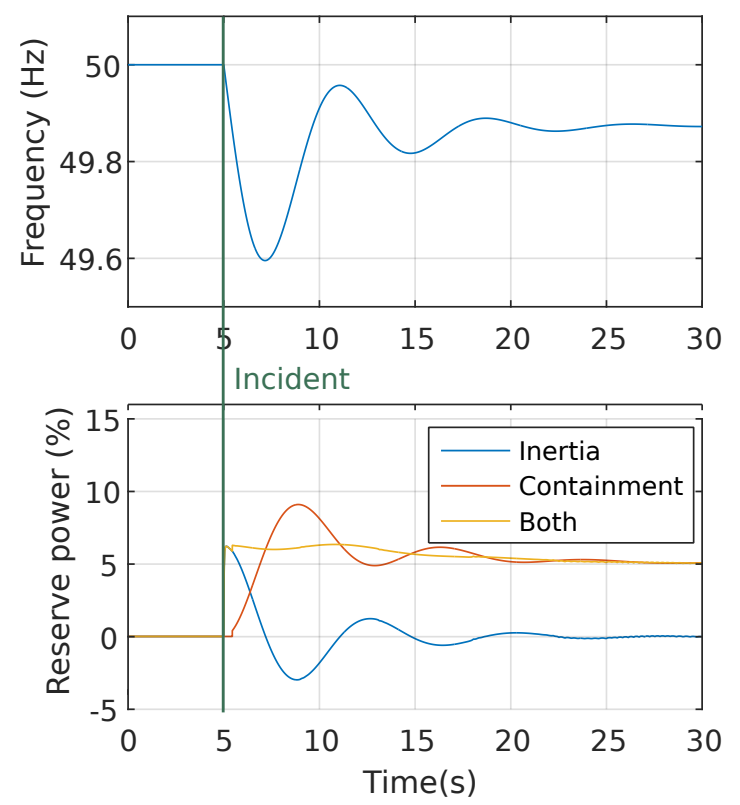

Fig. 6. Incident example: synthetic inertia and frequency sensitive response (containment response)
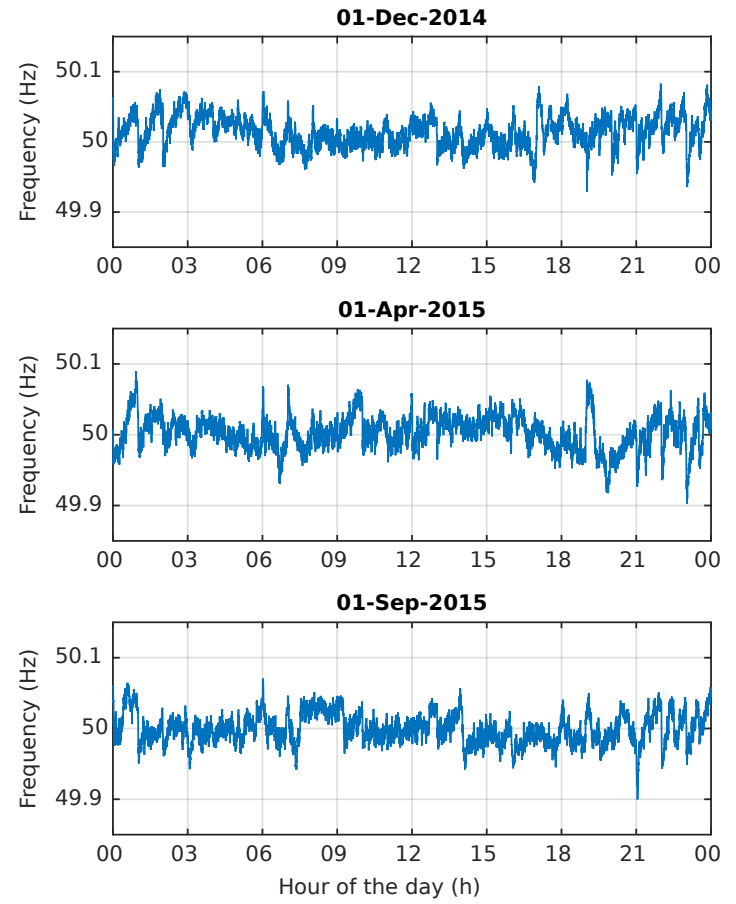

Fig. 7. Frequency as a function of the hour of the day for three different days

2015. To the best of our knowledge, such big frequency data were not freely accessible so far, which prevented some work on the frequency control. This signal is shown in Fig. 8.

The tendency to have similar frequency deviations at the same hour appears to be very important. The autocorrelation study (Fig. 9) confirms this with a more important correlation for a day lag than for an hour lag. This hour periodicity is linked with the way

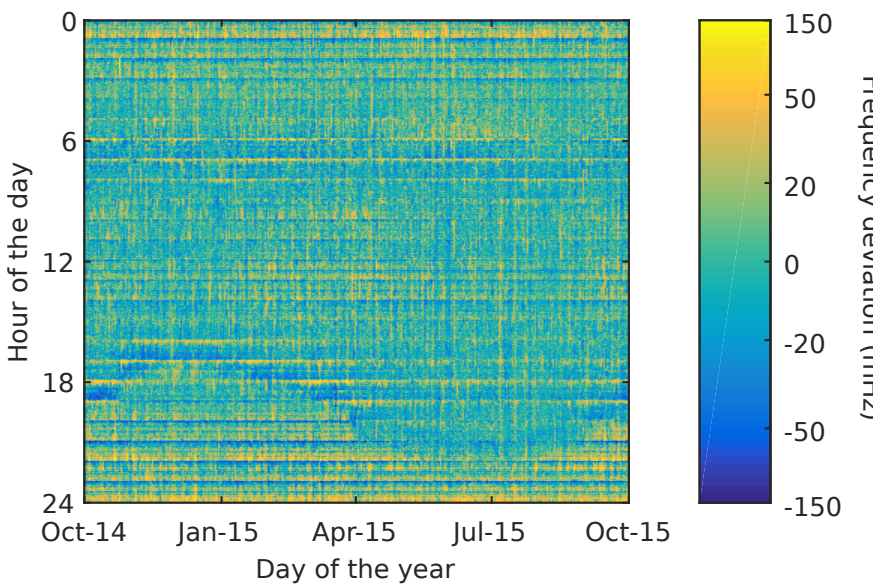

Fig. 8. Frequency deviation as a function of the hour and the date (year: 1st October 2014 to 30th September 2015)

the production is scheduled (at a one-hour time-step). Seasonal effects can also be seen, specially during the early morning (between 4 am and $6 \mathrm{am}$ ) and the evening (between $4 \mathrm{pm}$ and $8 \mathrm{pm}$ ).

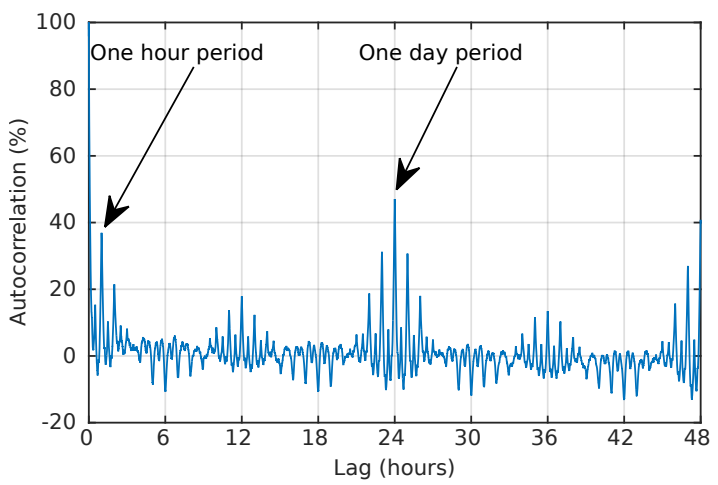

Fig. 9. Autocorrelation of the frequency deviation signal

It is important to analyze this signal in term of standard deviation and percentile values in order to study the classical use of the containment reserve (see Table IV and Fig. 10). The two months chosen for the table (March and August) represent respectively the biggest and the smallest standard deviation within the year considered.

TABLE IV. RTE FREQUENCY DEVIATION ANALYSIS (STANDARD DEVIATION, DEADBAND PROBABILITIES AND SEVEN-NUMBER SUMMARIES)

\begin{tabular}{|c|c|c|c|}
\hline Parameters & $08 / 2015$ & $03 / 2015$ & Year \\
\hline Std. dev. & $17.4 \mathrm{mHz}$ & $22.3 \mathrm{mHz}$ & $20.3 \mathrm{mHz}$ \\
\hline$p(|d|<10 \mathrm{mHz})$ & $45.06 \%$ & $35.32 \%$ & $39.14 \%$ \\
\hline$p(|d|<20 \mathrm{mHz})$ & $76.77 \%$ & $64.91 \%$ & $69.78 \%$ \\
\hline$p(|d|<30 \mathrm{mHz})$ & $92.14 \%$ & $84.38 \%$ & $87.69 \%$ \\
\hline$p C T L_{2} \%$ & $-35.2 \mathrm{mHz}$ & $-46.8 \mathrm{mHz}$ & $-41.4 \mathrm{mHz}$ \\
\hline$p C T L_{9} \%$ & $-22.3 \mathrm{mHz}$ & $-27.5 \mathrm{mHz}$ & $-25.3 \mathrm{mHz}$ \\
\hline$p C T L_{25} \%$ & $-12.1 \mathrm{mHz}$ & $-13.5 \mathrm{mHz}$ & $-13.0 \mathrm{mHz}$ \\
\hline$p C T L_{50} \%$ & $-1.2 \mathrm{mHz}$ & $1.3 \mathrm{mHz}$ & $-0.1 \mathrm{mHz}$ \\
\hline$p C T L_{75} \%$ & $+10.4 \mathrm{mHz}$ & $+15.7 \mathrm{mHz}$ & $+13.3 \mathrm{mHz}$ \\
\hline$p C T L_{91 \%}$ & $+22.5 \mathrm{mHz}$ & $+29.0 \mathrm{mHz}$ & $+26.4 \mathrm{mHz}$ \\
\hline$p C T L_{98} \%$ & $+37.3 \mathrm{mHz}$ & $+46.3 \mathrm{mHz}$ & $+43.4 \mathrm{mHz}$ \\
\hline
\end{tabular}

The analysis of the distribution shows a good fitting 

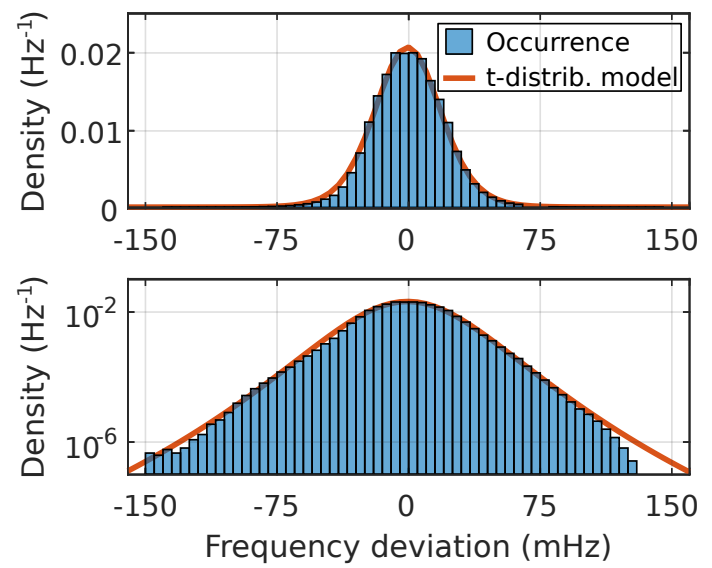

Fig. 10. Comparison between observed occurrences of the frequency deviation and t-distribution model with a linear and a logarithmic scale

with a Student's t-distribution. This distribution has been chosen instead of a more classical Gaussian distribution because it allows heavier tails. The parameters that shows the best fit correspond to a location parameter $\mu=-0.57 \mathrm{mHz}$, a scale parameter $\sigma=19 \mathrm{mHz}$ and a shape parameter $\nu=11$. First of all, we see that, even with a narrow deadband $( \pm 10 \mathrm{mHz})$, the deviation is smaller than this threshold more than one-third of the time.

This analysis allows the reproduction of the results presented in the following section, but can also be used to compare different synchronous area. An example of such a comparison is shown in Fig. 11 [28]. Clearly standard deviations of the frequency is more important for the Nordic area, the Ireland, the Great Britain and Cyprus.
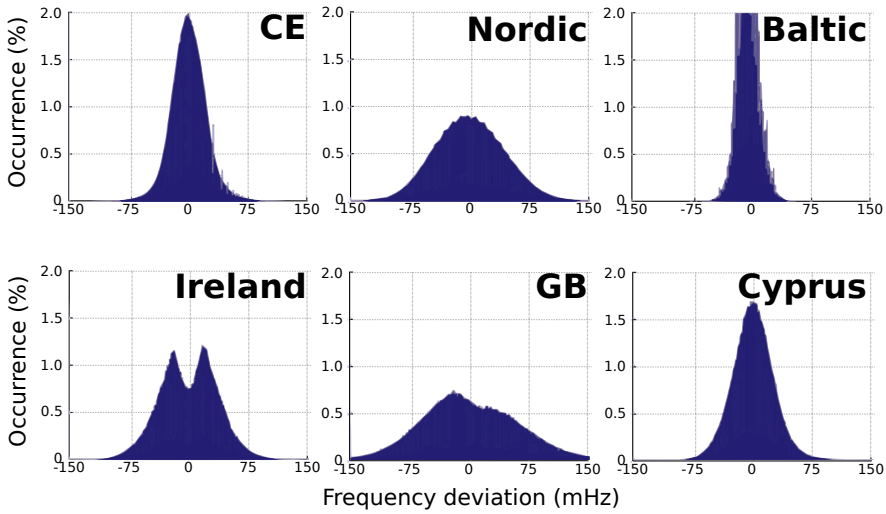

Fig. 11. Observed occurrence of the frequency deviation in different ENTSO-E synchronous areas during the year 2010 (2011 for the Ireland) [28]

\section{Income of the containment reserve}

In the following, we will consider only the expected income of a containment reserve. In this study, the value for the deadband equals $d b= \pm 10 \mathrm{mHz}$ and the droop is between $D=2 \%$ and $D=8 \%$ with a typical value of $D=4 \%$.

We will suppose here a quasi-static response of the generator based on the large time-step $(10 \mathrm{~s})$ of the frequency data. This is consistent with the values used previously in section III-A: with a $3 \mathrm{~s}$ time constant, the response is almost complete after $10 \mathrm{~s}(96 \%)$. However, less reactive response can be authorized, depending on the local grid code [?], [10], [24]. The time-step is too large for a study on synthetic inertia.

In the asymmetric case, we will analyze the influence of the reserve size $R_{c}$ on the income of this containment reserve. Two cases will be studied : the actual French case for marine energy, with a ratio between the reserve tariff and the feed-in tariff $\left(c_{f i}\right)$ of $r=0.12$ and the minimum French feed-in tariff for on-shore wind energy with $r=0.67$ (feed-in tariff of $28 € / \mathrm{MWh}$ ).

The optimistic hypothesis is made that a nonsymmetric reserve will be paid two times less than a symmetric reserve $\left(1 / 2 r c_{f i}\right)$. It will be noted that we consider a case where only the reserve availability is remunerate regardless of the dynamic or the droop. Part of the production will be lost compared to the maximum power production. It depends on the use of the containment reserve during the considered period, so the expected value of the asymmetric containment power will be used $\left(\mathbf{E}\left(\Delta P_{c}^{-}\right)\right.$, with $\Delta P_{c}^{-}$, the negative part of the containment reserve $\Delta P_{c}$, described in (8)). The expected value of the symmetric and asymmetric use of the containment reserve is shown in Fig. 12.

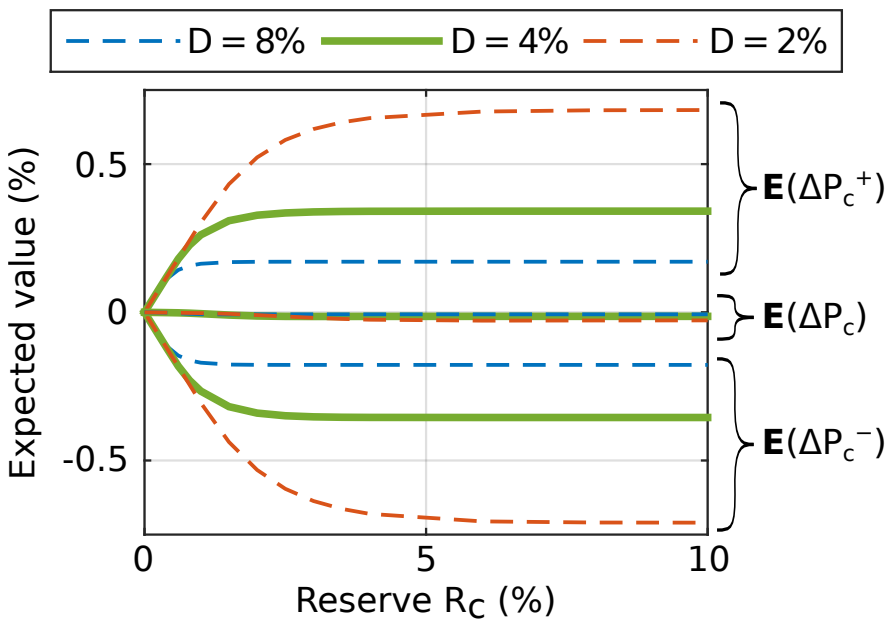

Fig. 12. Containment reserve expected value (positive part: $\mathbf{E}\left(\Delta P_{c}^{+}\right)$, total: $\mathbf{E}\left(\Delta P_{c}\right)$ and negative part: $\left.\mathbf{E}\left(\Delta P_{c}^{-}\right)\right)$as a function of the reserve capacity (normalized by $P_{\max }$ ) for three droop values

Finally, the expected value of the income $\mathbf{E}(\operatorname{Inc})$, considering both reserve remuneration and energy loss, 
is computed from this formulation :

$$
\mathbf{E}(\text { Inc })=\frac{1}{2} r c_{f i} P_{\max } R_{c}+c_{f i} \mathbf{E}\left(\Delta P_{c}^{-}\left(R_{c}, D\right)\right)
$$

The expected value in this case comes from the frequency data history.

This result can be normalized by $c_{f i} P_{\max }$ :

$$
\mathbf{E}\left(\frac{I n c}{c_{f i} P_{\max }}\right)=\frac{1}{2} r R_{c}+\mathbf{E}\left(\frac{\Delta P_{c}^{-}\left(R_{c}, D\right)}{P_{\max }}\right)
$$

The result is shown in Fig. 13 for different values of $D, R_{c}$ and $r$.
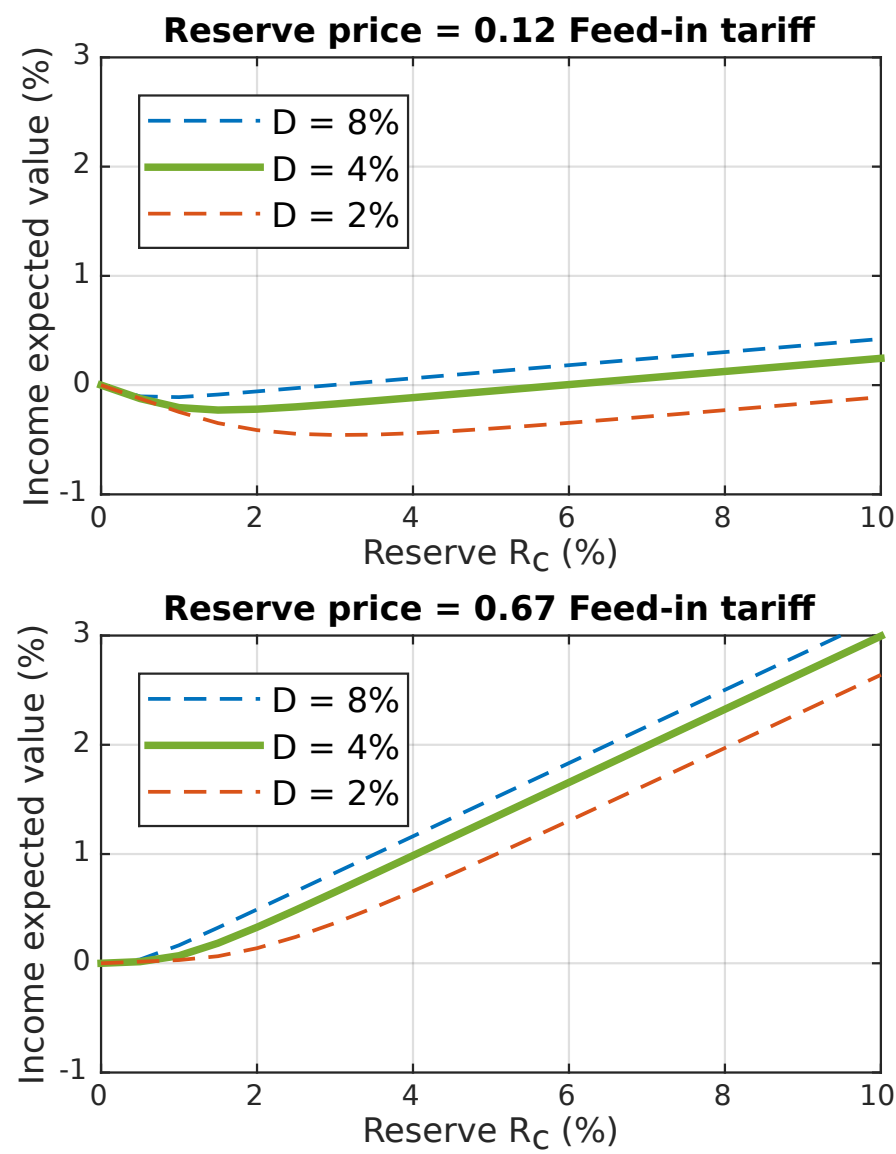

Fig. 13. Income expected value (normalized by the feed-in tariff with $P_{\max }$ ) for two tariff cases and three droop values as a function of the reserve capacity (normalized by $P_{\max }$ )

According to this figure, the expected income becomes positive when the reserve is large enough. Except in the worst case scenario (droop of $2 \%$ and important feed-in tariff compared to reserve price), a positive income is reached for a $10 \%$ reserve. In the first scenario, the income (corresponding to a cost when the value is negative) is relatively small.

However, in all these cases, it would be not possible to have a positive income with a symmetric reserve due to the necessary permanent deload (generation shedding) equals to the reserve $\left(R_{c}\right)$. Indeed, the symmetric case can be represented by this formula:

$$
\begin{aligned}
& \mathbf{E}\left(\frac{I n c}{c_{f i} P_{\max }}\right)=r R_{c}+\mathbf{E}\left(-R_{c}+\frac{\Delta P_{c}}{P_{\max }}\right) \\
& \mathbf{E}\left(\frac{I n c}{c_{f i} P_{\max }}\right) \approx \quad(r-1) R_{c}
\end{aligned}
$$

Indeed, the expected value of the containment reserve use in the symmetric case is near zero regardless the reserve size, the droop or the dynamic (see Fig. 12). Thus, the income of such symmetric reserve would be around $-0.88 \% / \%$ in the first case and $-0.33 \% / \%$ in the second case. This formula confirms that such symmetric reserve is economically interesting for an intermittent renewable generator only if the reserve tariff is superior to the feed-in tariff $(r>1)$.

\section{CONCLUSION}

The future grid code for generators concerning the frequency control in the ENTSO-E area have been detailed and explained: from a certain capacity threshold (dependent of the synchronous area), generators must emulate a synthetic inertia and participate to the frequency containment control (called frequency sensitive control).

The control laws used to participate to the grid resilience have been detailed with typical value and some techno-economic comments. In particular, the capabilities of different intermittent energy technologies concerning inertia synthesis (including tidal energy) must be assessed in future works, similarly to what have been done for wind turbines [19], [29].

The complementary of this two controls is tested on a test case in order to verify the different dynamics and steady-state response.

At the end of the paper, we analyze one year of frequency data in order to assess the potential income of a asymmetric frequency containment control participation (on the understanding that classical symmetric containment control cannot be economically interesting if the reserve price is less than feed-in tariff). Within the hypotheses taken here, this seems to be economically interesting in lots of cases to participate to this reserve.

The frequency data used in this study concern only the Continental Europe, that is only one part of the ENTSO$\mathrm{E}$ area. It could be interesting to use this method in the other synchronous area.

The comparison with the use of an energy storage system can also be interesting. Indeed, the decreasing 
cost of Energy Storage Systems may lead to a more economical way to increase grid resilience compared to generation shedding.

\section{ACKNOWLEDGMENTS}

This work has been supported by the PRISMER project, a project which received the support of the French National Environment and Energy Management Agency (ADEME) in the frame of the Investments for the Future Programme (Programme d'Investissements d'Avenir, PIA). The coordinator of this project is General Electric, and its purpose is the tidal turbines subsea electrical interconnection and power transmission from a farm. The investment in this project is $21 \mathrm{M} €$ for a duration of 4 years. Aside from General Electric, the other members of this project are: Engie, Silec Cable, Jifmar Offshore Services, Sector group, G2Elab and gipsa-lab.

\section{REFERENCES}

[1] Entso-E, "Electricity in Europe 2014: synthetic overview of electric system consumption, generation and exchanges in the entso-e area," 2015.

[2] R. Yan, T. K. Saha, N. Modi, N.-A. Masood, and M. Mosadeghy, "The combined effects of high penetration of wind and PV on power system frequency response," Applied Energy, vol. 145, pp. 320-330, 2015.

[3] P. Haessig, B. Multon, H. Ben Ahmed, S. Lascaud, and P. Bondon, "Energy storage sizing for wind power: impact of the autocorrelation of day-ahead forecast errors," Wind Energy, vol. 18, pp. 43-57, 2015.

[4] G. M. A. Delille, "Contribution du Stockage à la Gestion Avancée des systèmes Electriques : approches Organisationnelles et Technico-économiques dans les Réseaux de Distribution," Ph.D. dissertation, Ecole Centrale De Lille, 2010.

[5] P. Bousseau, R. Belhomme, E. Monnot, N. Laverdure, D. Boëda, D. Roye, and S. Bacha, "Contribution of windfarms to ancillary services," Conseil International des Grands Réseaux Electriques (CIGRE) General Meeting, no. November, 2006.

[6] X. Yingcheng and T. Nengling, "Review of contribution to frequency control through variable speed wind turbine," Renewable Energy, vol. 36, no. 6, pp. 1671-1677, 2011.

[7] F. Gonzalez-Longatt, E. Chikuni, and E. Rashayi, "Effects of the Synthetic Inertia from wind power on the total system inertia after a frequency disturbance," in Power Engineering Society Conference and Exposition in Africa (PowerAfrica), 2012 IEEE, Johannesburg, 2012, pp. 826-832.

[8] C. Rahmann and A. Castillo, "Fast Frequency Response Capability of Photovoltaic Power Plants: The Necessity of New Grid Requirements and Definitions," Energies, vol. 7, no. 10, pp. 6306-6322, 2014.

[9] F. Teng and G. Strbac, "Evaluation of Synthetic Inertia Provision from Wind Plants," in Power and Energy Society General Meeting, 2015 IEEE Energy Society General Meeting, 2015 IEEE, Denver, CO, 2015, pp. 1-5.

[10] Entso-E, "ENTSO-E Network Code for Requirements for Grid Connection Applicable to all Generators," p. 81, 2013.
[11] - "Entso-e at a glance: reliable, sustainable, connected," 2015.

[12] _ - "Implementation Guideline for Network Code: Requirements for Grid Connection Applicable to all Generators," 2013.

[13] P.M. Anderson and A.A. Fouad, Power System Control and Stability, 2nd ed. Wiley-IEEE Press, 2002.

[14] P. Tielens and D. van Hertem, "Grid Inertia and Frequency Control in Power Systems with High Penetration of Renewables," in Young Researchers Symposium in Electrical Power Engineering, no. 2, Delft (Netherlands), 2012, pp. 1-6.

[15] A. Hoke and D. Maksimovic, "Active power control of photovoltaic power systems," in Technologies for Sustainability (SusTech), 2013 1st IEEE Conference on, Portland, OR, 2013, pp. 70-77.

[16] J. Ekanayake and N. Jenkins, "Comparison of the response of doubly fed and fixed-speed induction generator wind turbines to changes in network frequency," Energy Conversion, IEEE Transactions on, vol. 19, no. 4, pp. 800-802, 2004.

[17] Q. C. Zhong and G. Weiss, "Synchronverters: Inverters that mimic synchronous generators," Industrial Electronics, IEEE Transactions on, vol. 58, no. 4, pp. 1259-1267, 2011.

[18] J. Morren, J. Pierik, and S. W. de Haan, "Inertial response of variable speed wind turbines," Electric Power Systems Research, vol. 76, no. 11, pp. 980-987, 2006.

[19] A. Teninge, C. Jecu, D. Roye, S. Bacha, J. Duval, and R. Belhomme, "Contribution to frequency control through wind turbine inertial energy storage," Renewable Power Generation, IET, vol. 3, no. 3, pp. 358-370, 2009.

[20] J. Morren, S. W. H. de Haan, W. L. Kling, and J. a. Ferreira, "Wind turbines emulating inertia and supporting primary frequency control," Power Systems, IEEE Transactions on, vol. 21, no. 1, pp. 433-434, 2006.

[21] GE Energy, "WindInertia Fact Sheet," 2009.

[22] N. Taveira (ENERCON), "Improving the grid compatibility with ENERCON Wind Energy converters," 2010.

[23] M. Fischer (ENERCON), "A wind turbine manufacturers view on international challenges and solutions for an optimized integration of wind power into power systems," 2013.

[24] National Grid Electricity Transmission, "The Grid Code," 2015.

[25] —- "Guidance Notes Power Park Modules," 2012.

[26] L. Ruttledge, N. W. Miller, J. O'Sullivan, and D. Flynn, "Frequency Response of Power Systems With Variable Speed Wind Turbines," Sustainable Energy, IEEE Transactions on, vol. 3, no. 4, pp. 683-691, 2012.

[27] RTE, "Operational data: Network frequency," 2015. [Online]. Available: http://clients.rte-france.com/lang/an/visiteurs/ vie/vie_frequence.jsp

[28] Entso-E, "NC Load Frequency Control \& Reserve : Overview last Developments," 2012.

[29] A. D. Hansen, M. Altin, I. D. Margaris, F. Iov, and G. C. Tarnowski, "Analysis of the short-term overproduction capability of variable speed wind turbines," Renewable Energy, vol. 68, pp. 326-336, 2014. 